\title{
Changes in reactive stratospheric gases due to a change in Brewer-Dobson circulation: results from a simple model
}

Article

Published Version

Cook, P. A. and Roscoe, H. K. (2011) Changes in reactive stratospheric gases due to a change in Brewer-Dobson circulation: results from a simple model. Atmospheric Science Letters, 13 (1). pp. 49-54. ISSN 1530-261X doi:

https://doi.org/10.1002/asl.362 Available at https://centaur.reading.ac.uk/34349/

It is advisable to refer to the publisher's version if you intend to cite from the work. See Guidance on citing.

To link to this article DOI: http://dx.doi.org/10.1002/asl.362

Publisher: John Wiley \& Sons

All outputs in CentAUR are protected by Intellectual Property Rights law, including copyright law. Copyright and IPR is retained by the creators or other copyright holders. Terms and conditions for use of this material are defined in the End User Agreement.

www.reading.ac.uk/centaur 
Central Archive at the University of Reading

Reading's research outputs online 


\title{
Changes in reactive stratospheric gases due to a change in Brewer-Dobson circulation: results from a simple model
}

\author{
Peter A. Cook and Howard K. Roscoe* \\ British Antarctic Survey/NERC, Cambridge, UK
}

*Correspondence to: H. K. Roscoe, British Antarctic Survey, Madingley Road, High Cross, Cambridge, CB3 OET, UK. E-mail: h.roscoe@bas.ac.uk

Received: 7 January 20 I I

Revised: 30 September 201 I

Accepted: 30 September 2011

\begin{abstract}
Amounts of source gases with stratospheric sinks ( $\left.\mathrm{CFCs}, \mathrm{N}_{2} \mathrm{O}, \mathrm{CH}_{4}\right)$ are affected by changes in Brewer-Dobson circulation. Source gases and their degradation products are important for atmospheric chemistry and climate. With a simple model, we examine how amounts and lifetimes of source gases and products depend on speed of the circulation. Transient results differ from steady-state and stratospheric results differ from those for stratosphere plus troposphere. Increases in speed increase the stratospheric burden of source gases, but reduce products and reduce total burdens and lifetimes of source gases. Copyright (c) 2011 Royal Meteorological Society
\end{abstract}

Keywords: stratosphere; Brewer-Dobson; trend

\section{Introduction}

The Brewer-Dobson circulation (Brewer, 1949; Dobson, 1956), whereby tropospheric air enters the stratosphere in the tropics, moves towards the winter pole, and returns via tropopause folds, is driven by the breaking of waves against the mean zonal wind in the stratosphere and mesosphere. After entry, air takes about 5 years to reach the polar stratosphere (Boering et al., 1996). The circulation speed will change with planetary and gravity wave intensities or the degree of their filtering, for example, due to increased greenhouse gases, and is predicted to increase over coming decades (Butchart et al., 2006).

Some longer lived trace gases $\left(\mathrm{CFCs}, \mathrm{N}_{2} \mathrm{O}, \mathrm{CH}_{4}\right)$ have sources near the ground, but have sinks in the stratosphere where they photo-oxidise to form reactive products $\left(\mathrm{Cl} y, \mathrm{NO} y, \mathrm{H}_{2} \mathrm{O}\right)$. When returned to the troposphere, the product gases are rapidly converted to soluble products $\left(\mathrm{HCl}, \mathrm{HNO}_{3}\right)$ and washed out by rain. Some source gases $\left(\mathrm{N}_{2} \mathrm{O}, \mathrm{CH}_{4}\right)$ also have sinks in the troposphere. Changes in speed of the Brewer-Dobson circulation will affect total lifetimes and burden of source gases (Butchart and Scaife, 2001) and their products, and because they are important to atmospheric climate and chemistry it is important to know how they will be affected.

There has been some disagreement as to how an increase in the Brewer-Dobson circulation will affect the stratospheric burdens of products. Some researchers have concluded that with a faster circulation there is greater exchange between troposphere and stratosphere so that more source gases are photooxidised at any one time, leading to shorter source lifetimes (Schauffler and Daniel, 1994; Butchart and Scaife, 2001). Others have argued that a slower circulation will lead to increased products because the source gas has a longer time to photo-oxidise in the stratosphere (Fish et al., 2000).

Simple models are required to obtain a better understanding of how amounts and lifetimes of trace gases are affected by changes in Brewer-Dobson circulation. General circulation models (GCMs) that include interactive chemistry are difficult to use as changes to forcing of the Brewer-Dobson circulation demand changes to initialisation that may change chemistry. Despite their group's access to a GCM, Ray et al. (2010) also designed a simplified model to investigate the results of changes in circulation.

Here, we show a simple model of the BrewerDobson circulation and trace gases. Its advantages are the few processes involved, the location and strength of the circulation are exactly defined, and there is only one source and product to consider.

\section{A simple model of the Brewer-Dobson circulation}

The model is shown in Figure 1. The ten stratospheric boxes can be seen as positions in a transect with a circuit of air passing through them, or as time steps in the stratospheric circuit of air. The mass flux is:

$$
\text { MassFlux }=M_{\mathrm{S}} / T_{\mathrm{S}}
$$

Within each stratosphere box the mass of source gas $\left(M_{\mathrm{S}} C_{\mathrm{S} x} / 10\right)$ is increased each time step $\left(T_{\mathrm{S}} / 10\right)$ by the mass flux from the previous box, and reduced by the mass flux to the next box and by photo-oxidation. A reasonably large number of boxes are required so that the time step is small enough to prevent large jumps in mixing ratio between adjacent boxes, ten being a 


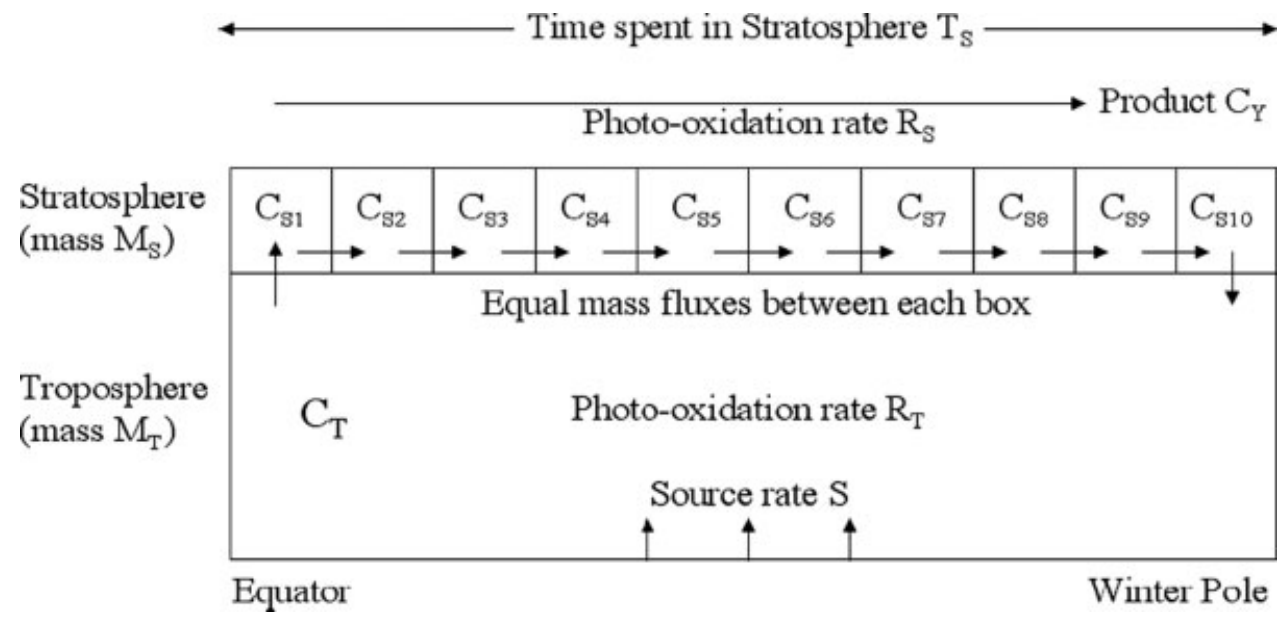

Figure I. Our simple model of Brewer-Dobson circulation and source gas with stratosphere sinks. The tropical and winter troposphere is a single well-mixed box containing air with source gas mixing ratio $C_{\mathrm{T}}$, source rate $S$ and decay rate $R_{\mathrm{T}}$. The stratosphere is represented by ten boxes, each containing air with mass $M_{S} / 10$, with source gas mixing ratios $C_{S I}$ to $C_{S \mid 0}$ and decay rate $R_{\mathrm{s}}$. Circulation is a single mass flux from troposphere to the first stratosphere box, then to each stratosphere box in turn before returning to the troposphere, spending time step $T_{S} / 10$ in each box. The product in the last stratosphere box is $C_{Y}$. Product is lost when air re-enters the troposphere but the remaining source gas is added to the tropospheric amount. Mass mixing ratios are used to simplify the mathematics.

good compromise. The source gas is photo-oxidised at a constant rate $R_{\mathrm{S}}$. Hence for boxes after the first:

$$
\begin{aligned}
& \Delta\left(M_{\mathrm{S}} C_{\mathrm{S} x} / 10\right)=\left(M_{\mathrm{S}} / T_{\mathrm{S}}\right) C_{\mathrm{S} x-1}\left(T_{\mathrm{S}} / 10\right) \\
& \quad-\left(M_{\mathrm{S}} / T_{\mathrm{S}}\right) C_{\mathrm{S} x}\left(T_{\mathrm{S}} / 10\right)-\left(M_{\mathrm{S}} / 10\right) C_{\mathrm{S} x} R_{\mathrm{S}}\left(T_{\mathrm{S}} / 10\right)
\end{aligned}
$$

Which reduces to:

$$
\Delta C_{\mathrm{S} x}=C_{\mathrm{S} x-1}-C_{\mathrm{S} x}-C_{\mathrm{S} x} R_{\mathrm{S}} T_{\mathrm{S}} / 10
$$

The resulting mixing ratio of the product in the polar stratosphere, $C_{\mathrm{Y}}$, is $C_{\mathrm{T}}$ minus $C_{\mathrm{S} 10}$. Products represent a sum whose subdivision is governed by sunlight and temperature (e.g. $\mathrm{NO} y=\mathrm{N}+\mathrm{NO}+\mathrm{NO}_{2}+$ $\mathrm{NO}_{3}+2 \mathrm{~N}_{2} \mathrm{O}_{5}+\mathrm{ClONO}_{2}+\mathrm{BrONO}_{2}+\mathrm{HO}_{2} \mathrm{NO}_{2}+$ $\mathrm{HNO}_{3}$ ).

$$
C_{\mathrm{Y}}=C_{\mathrm{T}}-C_{\mathrm{S} 10}
$$

The tropospheric mass of source gas $\left(M_{\mathrm{T}} C_{\mathrm{T}}\right)$ is increased each time step by the source $S$, reduced by air containing the source gas entering the stratosphere (mass flux times mixing ratio), increased by air returning to the troposphere after spending $T_{\mathrm{S}}$ in the stratosphere, and reduced by photo-oxidation in the troposphere with constant rate $R_{\mathrm{T}}$ :

$$
\begin{aligned}
& \Delta\left(M_{\mathrm{T}} C_{\mathrm{T}}\right)=S\left(T_{\mathrm{S}} / 10\right)-\left(M_{\mathrm{S}} / T_{\mathrm{S}}\right) C_{\mathrm{T}}\left(T_{\mathrm{S}} / 10\right) \\
& \quad+\left(M_{\mathrm{S}} / T_{\mathrm{S}}\right) C_{\mathrm{S} 10}\left(T_{\mathrm{S}} / 10\right)-M_{\mathrm{T}} C_{\mathrm{T}} R_{\mathrm{T}}\left(T_{\mathrm{S}} / 10\right)
\end{aligned}
$$

We could include variations in photo-oxidation with latitude and season, but for annual average global or polar mixing ratios, a mean photo-oxidation rate is adequate and it greatly simplifies the model.

Schauffler and Daniel (1994) developed a similar model, but with only four boxes for the troposphere plus stratosphere, and including both hemispheres with mass fluxes between them. Our model with 11 boxes and one-way mass flux is more realistic, and has a useful time delay in its response for studying transient effects.

\section{The model in steady-state conditions}

In steady state, the source $S$ and time $T_{\mathrm{S}}$ are constant, as are source and product mixing ratios, and $\Delta C_{\mathrm{S} x}$ and $\Delta M_{\mathrm{T}} C_{\mathrm{T}}$ are zero. The equations can then be solved analytically. Equation (2) reduces to:

$$
\frac{C_{\mathrm{S} x}}{C_{\mathrm{S} x-1}}=\frac{1}{1+R_{\mathrm{S}} T_{\mathrm{S}} / 10}
$$

Equation (4) to $S=C_{\mathrm{T}}\left[\left(\frac{M_{\mathrm{S}}}{T_{\mathrm{S}}}\right)\left(1-\frac{C_{\mathrm{S} 10}}{C_{\mathrm{T}}}\right)+M_{\mathrm{T}} R_{\mathrm{T}}\right]$ and from Equation (5):

$$
\frac{C_{\mathrm{S} 10}}{C_{\mathrm{T}}}=\left(\frac{1}{1+R_{\mathrm{S}} T_{\mathrm{S}} / 10}\right)^{10}
$$

Hence:

$$
C_{\mathrm{T}}=\frac{S}{\left[\left(\frac{M_{\mathrm{S}}}{T_{\mathrm{S}}}\right)\left(1-\left(\frac{1}{1+R_{\mathrm{S}} T_{\mathrm{S}} / 10}\right)^{10}\right)+M_{\mathrm{T}} R_{\mathrm{T}}\right]}
$$

From Equations (3) and (6):

$$
C_{\mathrm{Y}}=C_{\mathrm{T}}\left(1-\left(\frac{1}{1+R_{\mathrm{S}} T_{\mathrm{S}} / 10}\right)^{10}\right)
$$


And: $\quad C_{\mathrm{S}}=\frac{1}{10}\left[\frac{C_{\mathrm{T}}}{\left(1+R_{\mathrm{S}} T_{\mathrm{S}} / 10\right)}+\frac{C_{\mathrm{T}}}{\left(1+R_{\mathrm{S}} T_{\mathrm{S}} / 10\right)^{2}}\right.$ $\left.+\frac{C_{\mathrm{T}}}{\left(1+R_{\mathrm{S}} T_{\mathrm{S}} / 10\right)^{3}}+\ldots+\frac{C_{\mathrm{T}}}{\left(1+R_{\mathrm{S}} T_{\mathrm{S}} / 10\right)^{10}}\right]$

which is summed to:

$$
C_{\mathrm{S}}=\frac{C_{\mathrm{T}}}{R_{\mathrm{S}} T_{\mathrm{S}}}\left(1-\left(\frac{1}{1+R_{\mathrm{S}} T_{\mathrm{S}} / 10}\right)^{10}\right)
$$

Hence, changing the source produces a linear response in $C_{\mathrm{T}}, C_{\mathrm{Y}}$ and $C_{\mathrm{S}}$, but the result of changing the time spent in the stratosphere $T_{\mathrm{S}}$ (thereby changing the speed of circulation) is more complex. Increasing $T_{\mathrm{S}}$ reduces the mass flux, but increases the fraction of source photo-oxidised to stratospheric product.

While the mass flux has a linear response to changes in $T_{\mathrm{S}}$, the fraction of the source photo-oxidised follows an exponential decay and the response is less than linear, so doubling the time spent in the stratosphere does not lead to double the source being photooxidised. Therefore, increasing $T_{\mathrm{S}}$ increases $C_{\mathrm{T}}$ and $C_{\mathrm{Y}}$ but reduces $C_{\mathrm{S}}$, and $C_{\mathrm{Y}}$ has the greatest response to changes in $T_{\mathrm{S}}$.

The total burden $(B)$ of source is:

$$
B=M_{\mathrm{T}} C_{\mathrm{T}}+M_{\mathrm{S}} C_{\mathrm{S}}
$$

The total lifetime $(L)$ of the source, using Equations (6), (9) and (10), is:

$$
\begin{aligned}
L= & \frac{B}{S}=\frac{M_{\mathrm{T}} C_{\mathrm{T}}+M_{\mathrm{S}} C_{\mathrm{S}}}{S} \\
= & \frac{M_{\mathrm{T}}+\left(\frac{M_{\mathrm{S}}}{T_{\mathrm{S}}}\right) \frac{1}{R_{\mathrm{S}}}\left(1-\left(\frac{1}{1+R_{\mathrm{S}} T_{\mathrm{S}} / 10}\right)^{10}\right)}{M_{\mathrm{T}} R_{\mathrm{T}}+\left(\frac{M_{\mathrm{S}}}{T_{\mathrm{S}}}\right)\left(1-\left(\frac{1}{1+R_{\mathrm{S}} T_{\mathrm{S}} / 10}\right)^{10}\right)}
\end{aligned}
$$

The fraction of stratospheric photo-oxidation $\left(F_{\mathrm{S}}\right)$, using Equation (9), is:

$$
\begin{aligned}
F_{\mathrm{S}}= & \frac{M_{\mathrm{S}} C_{\mathrm{S}} R_{\mathrm{S}}}{M_{\mathrm{T}} C_{\mathrm{T}} R_{\mathrm{T}}+M_{\mathrm{S}} C_{\mathrm{S}} R_{\mathrm{S}}} \\
= & \frac{\frac{M_{\mathrm{S}}}{T_{\mathrm{S}}}\left(1-\left(\frac{1}{1+R_{\mathrm{S}} T_{\mathrm{S}} / 10}\right)^{10}\right)}{M_{\mathrm{T}} R_{\mathrm{T}}+\frac{M_{\mathrm{S}}}{T_{\mathrm{S}}}\left(1-\left(\frac{1}{1+R_{\mathrm{S}} T_{\mathrm{S}} / 10}\right)^{10}\right)}
\end{aligned}
$$

\section{Examining different trace gases}

We used the above steady-state equations to find the response of three separate source gases and their products to changes in circulation, with the ratio of tropospheric to stratospheric masses set to 10 - the global mean pressure at the tropopause gives about this value, and Schauffler and Daniel (1994) use 9. Details of the gases are given in Table I.

Results in Table II show that reducing $T_{\mathrm{S}}$ (increasing the speed) reduces $C_{\mathrm{T}}, C_{\mathrm{Y}}, B$ and $L$, but increases $C_{\mathrm{S}}$ and $F_{\mathrm{S}}$. With a faster circulation the mixing between the troposphere and stratosphere is more efficient and $C_{\mathrm{T}}$ and $C_{\mathrm{S}}$ are more similar, and with increased $C_{\mathrm{S}}$ photo-oxidation is greater. Although products are forming faster, $C_{\mathrm{Y}}$ is reduced because the greater mass flux cleans products out of the stratosphere faster than they are formed. Hence, increasing the speed of circulation does reduce the total burdens and lifetimes of source gases (consistent with Schauffler and Daniel 1994; Butchart and Scaife, 2001), but also reduces the products including that of $\mathrm{NO} y$ (consistent with Fish et al., 2000).

For CFC-12, which is entirely photo-oxidised in the stratosphere, $C_{\mathrm{T}}, C_{\mathrm{Y}}, B$ and $L$ all show large responses to changes in speed, $C_{\mathrm{Y}}$ has a near-linear response, but $C_{\mathrm{S}}$ is unchanged as stratospheric photo-oxidation must balances the source $S$. For $\mathrm{CH}_{4}$, only partly photo-

\begin{tabular}{|c|c|c|c|c|c|}
\hline Source gas & $\begin{array}{l}\text { Tropospheric volume } \\
\text { mixing ratios }\end{array}$ & $\begin{array}{l}\text { Tropospheric mass } \\
\text { mixing ratios }^{\mathrm{a}}\end{array}$ & Total lifetime & Where photo-oxidised & Product gas \\
\hline $\begin{array}{l}\text { CFC-12 } \\
\text { (molecular weight } \\
\text { of } \mathrm{Cl}=7 \mathrm{I} \text { ) }\end{array}$ & 540 pptv (WMO, 2007) & $1.33 \mathrm{ppbm}$ of $\mathrm{Cl}$ & 100 years (WMO, 2007) & All in stratosphere & Cly \\
\hline $\begin{array}{l}\mathrm{N}_{2} \mathrm{O} \text { (molecular } \\
\text { weight of } \mathrm{N}=28 \text { ) }\end{array}$ & 319 ppbv (WMO, 2007) & 309 ppbm of $N$ & 120 years (WMO, 2007) & Mostly in stratosphere & NOy \\
\hline $\begin{array}{l}\mathrm{CH}_{4} \text { (molecular } \\
\text { weight of } \mathrm{H}=4 \text { ) }\end{array}$ & 1777 ppbv (WMO, 2007) & $246 \mathrm{ppbm}$ of $\mathrm{H}$ & $\begin{array}{l}8 \text { years (Karlsdottir and } \\
\text { Isaksen, 2000) }\end{array}$ & Mostly in troposphere & $\mathrm{H}_{2} \mathrm{O}$ \\
\hline
\end{tabular}
oxidised in the stratosphere, the responses of $C_{\mathrm{T}}, B$ and $L$ are very small, but $C_{\mathrm{S}}, F_{\mathrm{S}}$ and $C_{\mathrm{Y}}$ have large responses. Responses for $\mathrm{N}_{2} \mathrm{O}$ are between those for CFC-12 and $\mathrm{CH}_{4}$.

Table I. The observed tropospheric mixing ratios of source gases, total lifetimes, where photo-oxidised, and products.

a volume mixing ratio $x$ molecular weight/28.9 
Table II. Steady-state results for different circulation speeds (different $T_{\mathrm{S}}$ ).

\begin{tabular}{|c|c|c|c|c|c|c|c|c|c|c|c|c|}
\hline Trace gas & $M_{T}$ & $R_{\mathbf{T}}$ & Ms & $R_{S}$ & $S$ & $T_{s}$ & $C_{T}$ & $C_{s}$ & $C_{Y}$ & B & $L$ & $F_{S}$ \\
\hline \multirow[t]{4}{*}{ CFC- 12} & 10 & 0 & 1 & 0.1585 & 0.142 & 7 & 1.53 & 0.90 & 0.99 & 16.16 & 113.9 & I \\
\hline & & & & & & 5 & 1.33 & 0.90 & 0.71 & 14.19 & 100.0 & 1 \\
\hline & & & & & & 3 & 1.15 & 0.90 & 0.43 & 12.35 & 87.0 & I \\
\hline & & & & & & 40.0 & 14.3 & 0.0 & 39.4 & 13.4 & 13.5 & 0.0 \\
\hline \multirow[t]{4}{*}{$\mathrm{N}_{2} \mathrm{O}$} & 10 & 0.001 & I & 0.1043 & 27.7 & 7 & 337 & 234 & 170 & 3604 & 130.0 & 0.878 \\
\hline & & & & & & 5 & 309 & 236 & 123 & 3326 & 120.0 & 0.889 \\
\hline & & & & & & 3 & 282 & 239 & 75 & 3056 & 110.3 & 0.898 \\
\hline & & & & & & 40.0 & 8.9 & 1.1 & 38.6 & 8.2 & 8.2 & I.I \\
\hline \multirow[t]{4}{*}{$\mathrm{CH}_{4}$} & 10 & 0.1227 & I & 0.1585 & 328 & 7 & 249 & 146 & 162 & 2632 & 8.02 & 0.070 \\
\hline & & & & & & 5 & 246 & 166 & 131 & 2626 & 8.00 & 0.080 \\
\hline & & & & & & 3 & 243 & 190 & 90 & 2619 & 7.98 & 0.092 \\
\hline & & & & & & 40.0 & 1.2 & 13.3 & 27.5 & 0.2 & 0.3 & 13.8 \\
\hline
\end{tabular}

Defined are: masses of air in troposphere and stratosphere $\left(M_{T}, M_{S}\right.$, arbitrary units), photo-oxidation rates ( $R_{T}$, $R_{S}$, fraction/year), source ( $S$, mass units/year), time spent in stratosphere ( $T_{S}$, years). Results are: mean mass mixing ratios of source $\left(C_{T}, C_{S}\right)$ and stratospheric product ( $C_{Y}$, all ppbm of $\mathrm{Cl}, \mathrm{N}, \mathrm{H})$, burden ( $\mathrm{B}$, mass units), lifetime ( $L$, years), fraction of photo-oxidation taking place in the stratosphere $\left(F_{\mathrm{S}}\right)$, size of changes when varying $T_{S}$ from 5 years (\%, in bold). Photo-oxidation rates and source terms are set to give the observed lifetimes and tropospheric mixing ratios at $T_{S}=5$ years.

For some source gases only a fraction of the photooxidised products are reactive - only $6 \%$ of $\mathrm{N}_{2} \mathrm{O}$ loss becomes $\mathrm{NO} y$, the remainder becoming $\mathrm{N}_{2}$. Mixing ratios and burdens of products would be reduced by the same fraction (by 0.06 for NOy). This does not affect the amount of source lost within each box as the nature of the product has no influence on the source, so mixing ratio and burden of source are unchanged. Only the amount of product needs to be reduced, and the accumulation of product in the final box is reduced by the same fraction. Relative changes in mixing ratio, and burden of reactive products between different scenarios, are unaffected. Factors other than the circulation speed can also change $\mathrm{NO} y$ - the trend in emission of $\mathrm{N}_{2} \mathrm{O}$ to the troposphere, and the temperature-dependent loss rate of NOy (Rosenfeld and Douglass, 1998).

Our model necessarily excludes mixing of air parcels that have travelled different routes through the stratosphere. But because mixing is a linear process, and because mass is conserved in our system, the results would be the same if air parcels travelling routes with different transit times, but the same average transit time, were mixed.

\section{The model in changing conditions}

Equations (1)-(4) can be cast in a model to be run as in Figure 1 to make transient calculations. As an example, we started the model for CFC-12 at steady state with $T_{\mathrm{S}}$ of 5 years with other parameters as in Table II.

Figure 2 shows the results. When $T_{\mathrm{S}}$ is reduced the $C_{\mathrm{S}}$ initially increase, reducing the differences between them as there is less time for photo-oxidation within each box, although changes take time to propagate through to all the boxes. Then $C_{\mathrm{T}}$ declines due to the greater mass flux, until the increase in $C_{\mathrm{S} 10}$ increases the CFC-12 returning to the troposphere, to give a

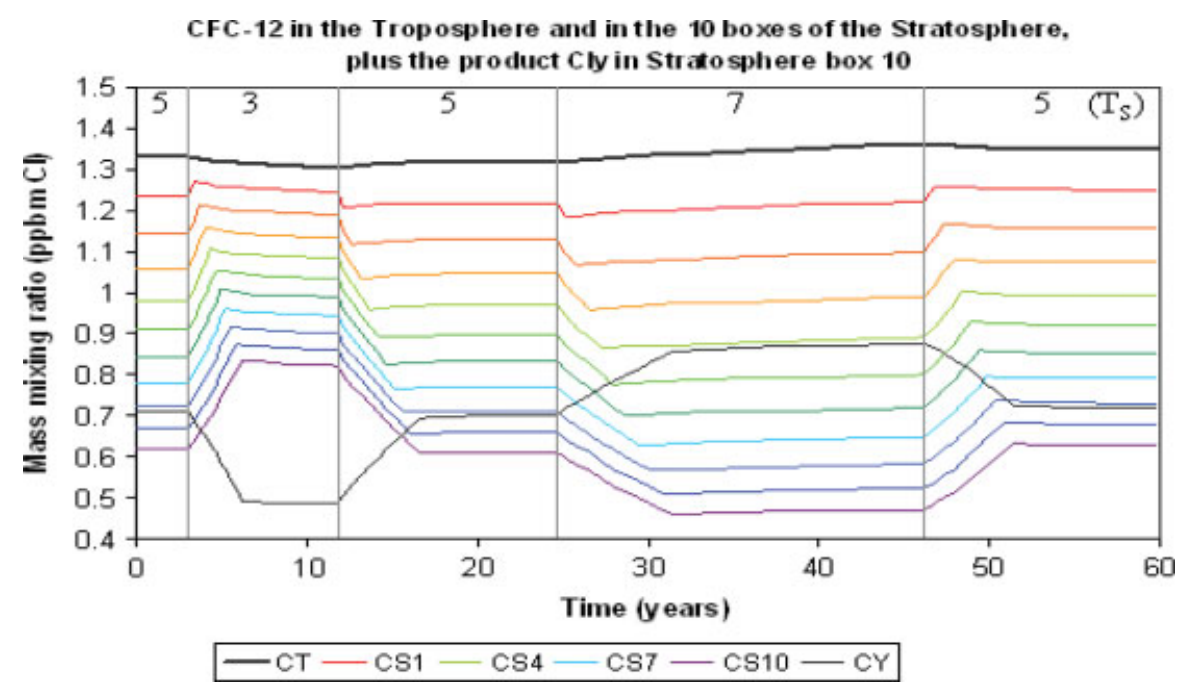

Figure 2. Mixing ratios (ppbm of $\mathrm{Cl}$ ) of CFC- 12 in the troposphere box $\left(C_{\mathrm{T}}\right)$ and in the stratosphere boxes $\left(C_{\mathrm{SI}}\right.$ to $\left.C_{\mathrm{S} I 0}\right)$, and of the product $\mathrm{Cly}$ in the final stratosphere box $\left(C_{Y}\right)$ during the model run. Steady-state values are given in Table II. The differences between the values in adjacent boxes show the exponential decay as CFC-12 is photo-oxidised within each stratosphere box. 


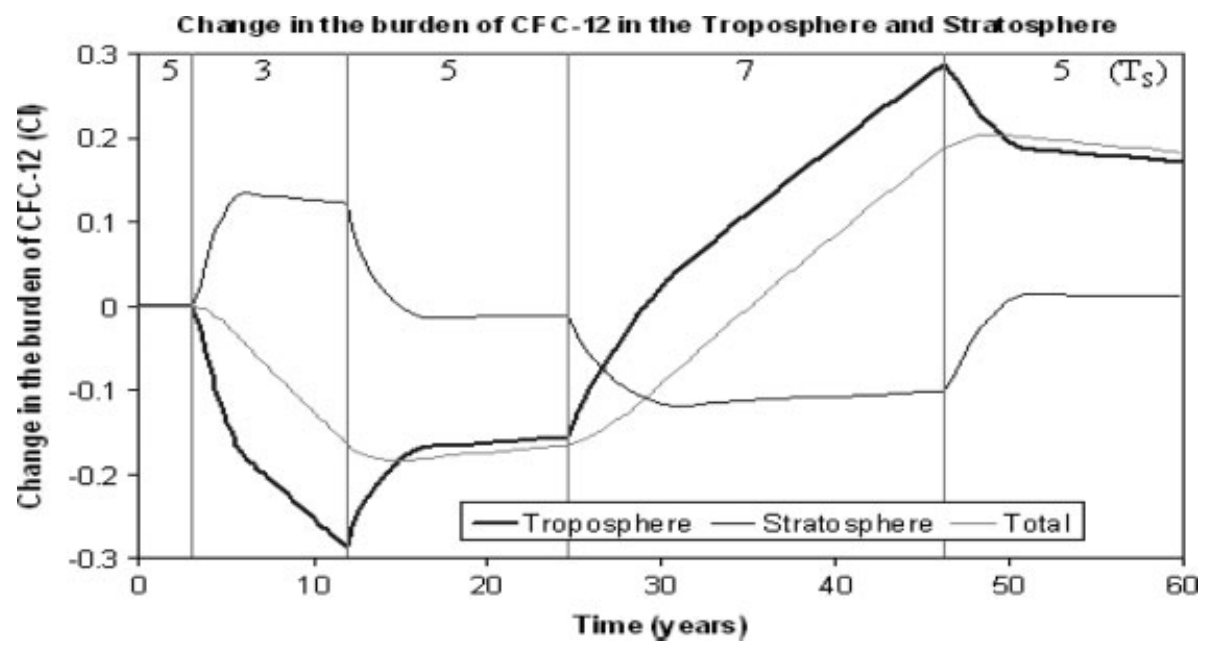

Figure 3. Changes in burdens of CFC-I 2 during the model run. Steady-state burdens are given in Table II.

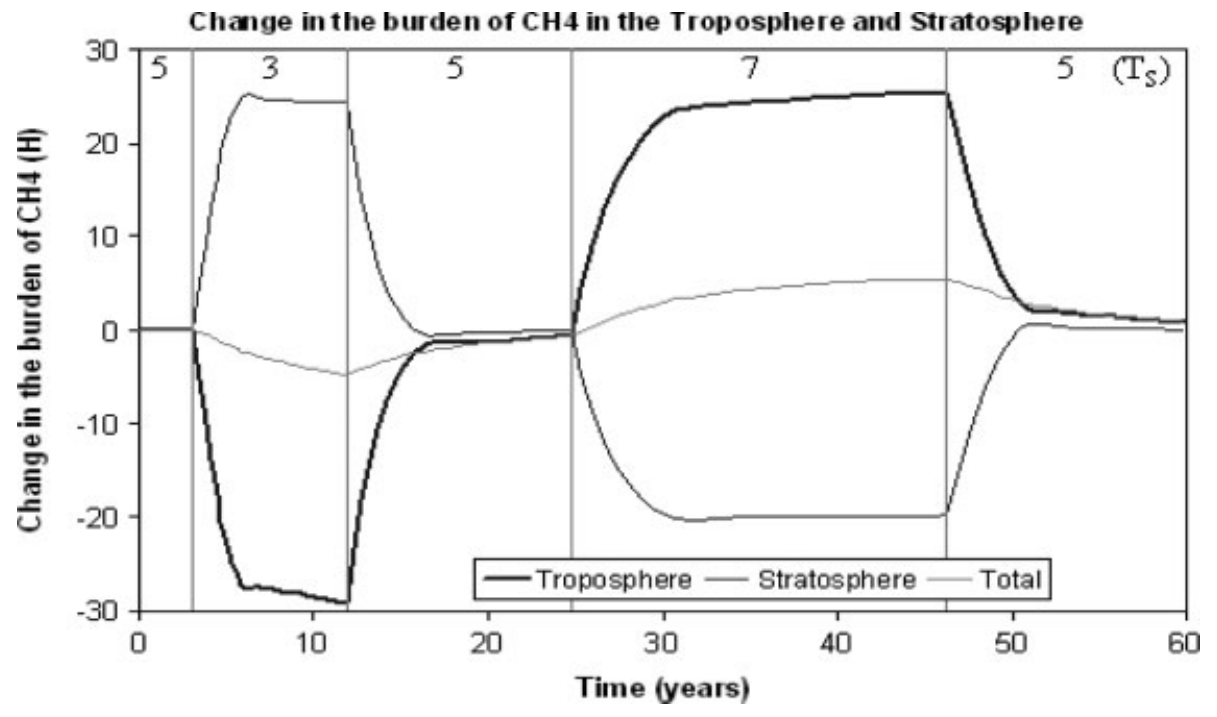

Figure 4. Changes in burdens of $\mathrm{CH}_{4}$ during the model run. Steady-state burdens are given in Table II.

new balance with a reduced tropospheric but increased stratospheric burden of CFC-12. This also leads to slight reductions in $C_{\mathrm{S} 1}$ to $C_{\mathrm{S} 10}$. There is then a slow decline in all mixing ratios as CFC-12 is now photooxidised at a faster rate overall. $C_{\mathrm{T}}$ would eventually reach a new steady-state value (Table II), but the response is slow due to the large mass of air in the troposphere - only $11 \%$ of the way to its final value after time $T_{\mathrm{S}}$.

The mixing ratio of the products $\mathrm{Cl} y\left(C_{\mathrm{Y}}\right)$ responds at the same rate as $C_{\mathrm{S} 10}$ to changes in $T_{\mathrm{S}}$. Reducing $T_{\mathrm{S}}$ results in a reduction in $\mathrm{Cl} y$ as less CFC-12 is photooxidised, then a slow decline as all mixing ratios and the total burden are reduced, $\mathrm{Cl} y$ would eventually reach a new steady state (Table II) but the response is much quicker than for $C_{\mathrm{T}}$ and it is $78 \%$ of the way there after time $T_{\mathrm{S}}$. With the greater mass flux through the stratosphere more $\mathrm{Cly}$ is being produced, but it is then cleaned out faster so that the mixing ratio is reduced. When $T_{\mathrm{S}}$ is restored there is a general reversal, and an inverted pattern is seen.
Figure 3 shows the changes in burdens. Reducing $T_{\mathrm{S}}$ first reduces tropospheric CFC-12 but increases it in the stratosphere due to the greater mass flux, then the burden slowly declines in both. CFC-12 is photooxidised at a faster rate overall as a larger fraction of the CFC-12 is in the stratosphere, but this is more noticeable in the troposphere as it contains most of the air. The burden would eventually reach a new steady state (Table II). Increasing $T_{\mathrm{S}}$ produces a similar but inverted pattern.

The model was also run with $\mathrm{N}_{2} \mathrm{O}$ and $\mathrm{CH}_{4}$. Results for $\mathrm{N}_{2} \mathrm{O}$, mostly photo-oxidised in the stratosphere, are very similar to those for CFC-12. Results for $\mathrm{CH}_{4}$, mostly photo-oxidised in the troposphere, have significant differences, shown in Figure 4. The tropospheric mixing ratio of $\mathrm{CH}_{4}$ and its total burden do not change as much as CFC-12, but with the much shorter total lifetime, the source and product mixing ratios and total burden respond more quickly to changes in speed. After time $T_{\mathrm{S}}, C_{\mathrm{T}}$ is over $88 \%$ of the way to the new steady state, and $C_{\mathrm{Y}}$ is over $94 \%$ of the way. 


\section{Conclusions}

Changes in Brewer-Dobson circulation will change total atmospheric burdens of trace gases and their lifetimes. The results from this simple model imply that, with an increased circulation, a larger fraction of source gas resides in the stratosphere, so its photo-oxidation rate is increased thereby reducing the total burden and lifetime (consistent with Schauffler and Daniel, 1994). An increased circulation leads to CFCs being removed from the atmosphere at a faster rate (consistent with Butchart and Scaife, 2001).

An increased circulation also results in the products being formed at a faster rate, but with the increased mass flux the products are cleaned out of the stratosphere at an even faster rate, so their mixing ratios and stratospheric burdens are reduced (consistent with Fish et al., 2000). Hence a faster circulation results in less stratospheric NOy (consistent with Roscoe, 2004). The stratospheric mixing ratios of the products are reduced more than the tropospheric mixing ratios of the source, and with a quicker response.

For $\mathrm{CH}_{4}$, an increased circulation results in only a small reduction in burden and lifetime, although its short lifetime ensures rapid responses.

\section{Acknowledgements}

We thank the EU for funding GEOMON (contract 036677), Adrian Tuck for suggesting alternative viewpoints and Eric W. Wolff for checking consistency of units.

\section{References}

Boering KA, Wofsy SC, Daube BC, Schneider HR, Loewenstein M, Podolske JR, Conway TJ. 1996. Stratospheric mean ages and transport rates from observations of carbon dioxide and nitrous oxide. Science 274: 1340-1343.

Brewer AW. 1949. Evidence for a world circulation provided by the measurements of helium and water vapour distribution in the stratosphere. Quarterly Journal of the Royal Meteorological Society 75: $351-363$.

Butchart N, Scaife AA. 2001. Removal of chlorofluorocarbons by increased mass exchange between the stratosphere and troposphere in a changing climate. Nature 410: 799-802.

Butchart N, Scaife AA, Bourqui M, de Grandpré J, Hare SHE, Kettleborough J, Langematz U, Manzini E, Sassi F, Shibata K, Shindell D, Sigmond M. 2006. Simulations of anthropogenic change in the strength of the Brewer-Dobson circulation. Climate Dynamics 27: $727-741$.

Dobson GMB. 1956. Origin and distribution of polyatomic molecules in the atmosphere. Proceedings of the Royal Society of London $\mathbf{A}$ 236: $187-193$.

Fish DJ, Roscoe HK, Johnson PV. 2000. Possible causes of stratospheric $\mathrm{NO}_{2}$ trends observed at Lauder, New Zealand. Geophysical Research Letters 27: 3313-3316.

Karlsdóttir S, Isaksen ISA. 2000. Changing methane lifetime: possible cause for reduced growth. Geophys. Res. Lett. 27, DOI: 10.1029/1999GL010860.

Ray EA, Moore FL, Rosenlof KH, Davis SM, Boenisch H, Morgenstern O, Smale D, Rozanov E, Hegglin M, Pitari G, Mancini E, Braesicke P, Butchart N, Hardiman S, Li F, Shibata K, Plummer DA. 2010. Evidence for changes in stratospheric transport and mixing over the past three decades based on multiple data sets and tropical leaky pipe analysis. Journal of Geophysical Research 115 : D21304. DOI: 10.1029/2010JD014206.

Roscoe HK. 2004. A review of stratospheric $\mathrm{H}_{2} \mathrm{O}$ and $\mathrm{NO}_{2}$. Advance in Space Research 34: 1747-1754.

Rosenfeld JE, Douglass AR. 1998. Doubled CO2 effects on NOy in a coupled 2D model. Geophysical Research Letters 25: 4381-4384.

Schauffler SM, Daniel JS. 1994. On the effects of stratospheric circulation changes on trace gas trends. Journal of Geophysical Research 99: 25747-25754.

WMO (World Meteorological Organisation). 2007. Scientific Assessment of Ozone Depletion 2006, Global Ozone Research and Monitoring Project, Report No.50. WMO: Geneva, Switzerland. 